\title{
GLOBALIZAÇÃO ECONÔMICA: ANÁLISE DOS EFEITOS JURÍDICOS E ECONÔMICOS NO MERCADO PÓS REFORMA TRABALHISTA
}

\author{
ECONOMIC GLOBALIZATION: ANALYSIS OF THE LEGAL AND ECONOMIC \\ EFFECTS ON THE MARKET AFTER LABOR REFORM
}

\author{
LUCIANA DE ABOIM MACHADO' \\ ROBERT THOMÉ NETO ${ }^{2}$
}

\section{RESUMO:}

O presente trabalho analisa os efeitos jurídicos e econômicos da Reforma Trabalhista como manifestação da globalização econômica. Para tanto, foi utilizado o método dedutivo-dialético, pelo qual serão aplicados textos constantes de livros, artigos e publicações jurídicas e econômicas, no geral, abordando o referido tema. Ainda, com relação aos efeitos econômicos, analisou dados estatísticos com relação à comparação do período anterior e posterior à vigência da nova lei, a fim de se verificar a existência de uma possível correlação entre crescimento econômico e flexibilização da legislação laboral. Os resultados alcançados demonstram que a globalização econômica busca, como fim último, o mercado a serviço do capital. Para isso, adota-se um modelo de sistema cuja eficiência econômica se caracteriza como valor social supremo, ou seja, concentra-se no economicismo, no sentido de sobrevalorizar aspectos econômicos em detrimento daqueles sociais. Contudo, após análise de dados estatísticos, observa-se que, na prática, inexiste correlação entre flexibilizar a legislação trabalhista e crescimento econômico.

Palavras-chave: Economia; Direito; Globalização; Flexibilização; Trabalho.

\begin{abstract}
:
1Pós-doutora em Direito pela Universidade Federal da Bahia e pela Università Degli Studi G. dAnnunzio (Italia). Doutora em Direito do Trabalho pela Faculdade de Direito da Universidade de São Paulo. Mestre em Direito do Trabalho. Especialista em Direito do Trabalho e em Direito Processual Civil, pela Pontifícia Universidade Católica de São Paulo. Tem experiência na área de Direito, com ênfase em Direitos Internacional dos Direitos Humanos, Direito do Trabalho e Formas Adequadas de solução de conflitos. Professora Associada da Universidade Federal de Sergipe. Coordenadora do Programa de Pós-Graduação "stricto sensu" em Direito da Universidade Federal de Sergipe.

2 Mestrando pelo Programa de Direito Empresarial e Cidadania; Pós-Graduando em Direito Tributário e Processo Tributário; Pós-Graduado em Direito Aduaneiro; Bacharel em Direito. Todas pela Faculdade de Direito de Curitiba (UNICURITIBA). Advogado. Sócio Fundador do escritório Basso, Boletta, Sureck \& Thomé Advocacia e Consultoria Jurídica; Membro do Grupo de Estudos igualdade, discriminação e trabalho no Unicuritiba e Membro da Comissão de Direito do Consumidor e Membro do Observatório Tarifário da OAB-PR, 2019.
\end{abstract}


This paper analyzes the legal and economic effects of Labor Reform as a manifestation of economic globalization. For this, the deductive-dialectic method was used, by which texts from books, articles and legal and economic publications will be applied, in general, addressing the referred theme. Still, with regard to economic effects, it analyzed statistical data in relation to the comparison of the period before and after the new law was in force, in order to verify the existence of a possible correlation between economic growth and easing of labor legislation. The results achieved demonstrate that economic globalization seeks, as the ultimate goal, the market at the service of capital. For this, a system model is adopted whose economic efficiency is characterized as supreme social value, that is, it focuses on economicism, in the sense of overvaluing economic aspects to the detriment of those social. However, after analyzing statistical data, it is observed that, in practice, there is no correlation between easing labor legislation and economic growth.

Keywords: Economy; Right; Globalization; Flexibility; Job.

\section{INTRODUÇÃO}

O presente trabalho tem por objetivo, pois, investigar em que medida a flexibilização da legislação trabalhista, como manifestação da globalização econômica, garante, de fato, um efetivo crescimento econômico.

Para tanto, será utilizado o método dedutivo-dialético, pelo qual serão aplicados textos constantes de livros, artigos e publicações jurídicas e econômicas, no geral, abordando o referido tema. Ainda, com relação aos efeitos econômicos, será analisado dados estatísticos com relação à comparação do período anterior e posterior à Reforma Trabalhista, Lei no 13.467/2017, no que diz respeito à empregabilidade brasileira.

Nesse sentido, com relação à Constituição brasileira, os artigos 170 e 193 destacam, respectivamente, os princípios gerais da ordem econômica e da ordem social, declarando que o Estado brasileiro tem compromissos formalmente explicitados no tocante à valorização do trabalho humano e com relação à justiça social.

Nesse sentido, o Direito do Trabalho, dentre outras necessidades sociais, passou a atuar na subsistência do empregado por uma questão de dignidade da pessoa humana e valorização do trabalho humano. Entretanto, a Lei 13.467/2017, popularmente conhecida como Reforma Trabalhista, flexibilizou substancialmente a legislação laboral no Brasil, de maneira que teve como principal motivação viés, sobretudo, econômico, por ser forte tendência dentro dos quadros de um marcado cada vez mais influenciado e globalizado.

Assim, a legislação trabalhista, sob influência econômica, passa a ser, agora e, sobretudo, o que as partes criarem. Isso porque, menos que um código de leis pelo Estado, terá uma compilação de acordos e convenções coletivas de trabalho e de acordos individuais de 
trabalho. E, serão essas as regras que irão, primordialmente, reger as relações de convivência entre trabalhadores e patronos no Brasil (SOUSA FILHO, 2019).

Entretanto, as pesquisas demonstram que a presunção econômica de flexibilizar e desregulamentar a legislação trabalhista com o intuito de criação e manutenção de postos de trabalho não se sustenta, na medida em que a pobreza abarcada pela flexibilização e desregulamentação em nada ajuda o crescimento econômico. Isso, pois, o consumidor final, que movimenta e aquece o mercado, é o próprio trabalhador.

\section{INTERVENÇÃO MÍNIMA COMO REFLEXO DA GLOBALIZAÇÃO ECONÔMICA E O ESTADO SOCIAL BRASILEIRO.}

O cenário da globalização proporciona condições para a consolidação do fenômeno da mundialização econômica do mercado. $\mathrm{O}$ acirramento da concorrência internacional, o aumento da acumulação de riqueza em contraponto às desigualdades regionais e sociais, a diminuição do intervencionismo estatal em contraponto às ideologias neoliberais são alguns dos fenômenos que, consequentemente, alteram e influenciam as relações de trabalho.

Portanto, caminha-se no sentido de um novo quadro político econômico social, marcado por forte influência da globalização econômica de mercado ao adotar teorias, com ideologia utilitarista, em busca do crescimento econômico. Ou seja, os mercados globalizados buscam substituir o Estado, de maneira que a legitimidade do direito passa a se apoiar em fatores econômicos.

A própria concepção de Estado-soberano parece trilhar sua erosão, na medida em que começa a apresentar pouco controle de sua respectiva economia nacional, em razão de sua insuficiência frente ao mercado a serviço do capital globalizado.

Os Estados, bem como a economia nacional, ficam submetidos involuntariamente ao jogo da globalização cujas regras os ultrapassam. Nesse jogo, em que a economia se apresenta como tabuleiro, uma das faces do dado prevê o afastamento estatal das relações sociais.

Nesse sentido, é manifesta a existência de forte movimento ajustado no economicismo, na medida em que se procura explicar fenômenos e fatos sociais em função de interesses e necessidades econômicas. Ou seja, quando a própria economia busca explicar o direito sobrevalorizando aspectos econômicos.

As conquistas dos Direitos Trabalhistas, tais como temos hoje, concretizaram-se, somente, em razão da função regulatória do Estado. Ou seja, somente com a fixação da 
legislação trabalhista, como estrutura jurídica normativa, desenvolveu-se cultura em torno do respeito a determinadas condições de trabalho.

É nessa percepção que se sustentou a necessidade da intervenção estatal nas relações trabalhistas, operando como contrapeso frente ao desequilíbrio existente no liame empregadoempregador. O constituinte privilegiou o modelo capitalista, contudo, garantiu a finalidade da ordem econômica ao assegurar a todos existência digna, conforme ditames da justiça social (LENZA, 2011).

Assim, para a tutela dos direitos trabalhistas a fim de garantir-lhes proteção em um cenário desfavorável e desproporcional, faz-se necessária à presença estatal por intermédio do Poder Judiciário, na medida em que se depara com a realidade posta e não com aquela realidade pressuposta textualizada na letra da lei (MARTINS, GUNTHER E VILLATORE, 2019).

Para tanto, o Direito do Trabalho, em última análise, atua na subsistência do empregado por uma questão de dignidade da pessoa humana, valorização do trabalho humano, dentre outros princípios e razões que, igualmente, estão previstos nos laços do domínio econômico e social da Constituição brasileira.

Nesse sentido, a Lei 13.467/2017, denominada de Reforma Trabalhista, alterou substancialmente a CLT no Brasil. Sua principal motivação não foi jurídica, vez que o viés econômico se sobrepôs ao direito.

A maior preocupação rastreia em torno do embrião deontológico adotado pela referida lei. A essência da Reforma Trabalhista se caracterizou no princípio da intervenção mínima do Estado. Ou seja, buscou enfraquecer e, até mesmo, afastar a função regulatória e fiscalizatória do Estado, ao redefini-la para aquela concepção absenteísta.

Assim, se alterou de maneira profunda as relações sociais de trabalho, sob a ótica não só da segurança, mas com relação ao meio ambiente e saúde do trabalho, pois se possibilitou legalizar aspectos contratuais, salariais e condicionais que, quando ocorriam, eram tomados como ilegais.

Em síntese, a receita da reforma trabalhista priorizou, como ingrediente principal, a intervenção mínima. Nessa ótica, quando se defende que o acordado vale mais que o legislado, colocam-se em pé de igualdade, para livre negociação, dois polos aos quais tanto a história quanto a própria legislação já demonstraram serem desiguais.

O referido princípio está positivado no artigo $8^{\circ}, \S 3^{\circ}$, segunda parte, da CLT, ao estipular que: “A Justiça do Trabalho [...] balizará sua atuação pelo princípio da intervenção mínima na autonomia da vontade coletiva” (BRASIL, 2017). 
Dentre outros, é possível identificar reflexos nos artigos 444 e 611-A da CLT, ao qual elencaram as possibilidades em que o negociado se sobrepõe ao legislado. Denota-se que os referidos artigos estão, portanto, assentados na ideia de última ratio da atuação estatal nas relações trabalhistas.

No viés legalista e normativo, o referido princípio fundamenta-se e adequa-se às novas relações que se estabelecem em razão da globalização econômica de mercado, e, isso se explica pela menor intervenção estatal nas relações humanas. (MARTINS; GUNTHER; VILATORE, 2019).

Os artigos 611-A e 611-B da CLT, alterada pela nova lei, cuidam da prevalência da norma negociada sobre a disposições legais em vigor. Ao cabo, é fortalecida a autonomia privada coletiva e capital e trabalho ficam em pé de igualdade. Mas, o problema não é ficar em pé, a questão é a igualdade, que não existe (SOUSA FILHO, 2010).

Portanto, o direito do trabalho, sob influência econômica, passa a ser, agora e sobretudo, o que as partes criarem. Isso porque, menos que um código de leis pelo Estado, terá uma compilação de acordos e convenções coletivas de trabalho e de acordos individuais de trabalho. E, serão essas as regras que irão, primordialmente, reger as relações de convivência entre trabalhadores e patronos no Brasil. (SOUSA FILHO, 2019).

A propósito da modernização, o que se pretende por esse mecanismo manipulatório e instrumental é um ajuste neoliberal substancial da disciplina do trabalho para promover maior liberdade de empreender do empregador, com maior poder unilateral. Com isso se mercantiliza a relação salaria e fragiliza a negociação coletiva e a ação sindical. (MACHADO, 2019).

É nesse sentido que a Lei $13.467 / 2017$ representa manifesta ruptura com o pacto constituinte de 1988 em termos de democratização das relações de trabalho. O acordo coletivo de trabalho, por exemplo, pode tornar-se a nova lei do trabalho no Brasil, na medida em que podemos ter uma legislação diferente para cada empresa, pois será nela o local ao qual se passará a definir salários, jornadas, adicionais, entre outros (SOUSA FILHO, 2019).

Importante recordar que a supremacia da Constituição na ordem jurídica é uma conquista institucional, jurídica, política e cultural. Nesse quadro, a interpretação e a compatibilização de qualquer diploma normativo aprovado em um Estado Democrático de Direito tem de passar pelo estrito respeito aos princípios, regras e institutos constitucionais, independentemente da força de convencimento societário, cultural ou político. (DELGADO e DELGADO, 2019) 
A própria Constituição, em seu artigo 174 atribuiu ao Estado o objetivo de promover atuação estatal de caráter normativo e regulamentar, capaz de assegurar efetividade às finalidades da atividade econômica pautada na garantia da justiça social.

Ainda, vale lembrar que a Constituição de 1988, no caput de seu artigo $7^{\circ}$, indica que o rol de direitos trabalhistas é assegurado, sem prejuízo de outros que visem melhorar a condição social dos trabalhadores. Significa dizer que há um contrato mínimo a ser venerado, de maneira que esvaziá-lo, por iniciativa do Poder Legislativo, ao intervir com lei que, por sua vez, abarca o preceito da intervenção mínima, veio a ferir, inclusive, a própria Constituição de 1988 (MARTINS; GUNTHER; VILATORE, 2019).

Portanto, uma vez que o modelo previsto pelo Constituinte de 1988 e assumido pelo Estado brasileiro, configura-se num viés de livre iniciativa, contudo, assentada no contexto do domínio social, significa dizer que embora seja inegável a necessidade de incentivo à econômica de mercado, isso não se deve em detrimento ao sufocamento dos direitos sociais. Situação essa, perceptível no princípio da intervenção mínima abarcado pela Reforma Trabalhista.

Assim, a globalização econômica representa novo quadro político econômico social, marcado pela visão utilitarista no caminho para o crescimento econômico, de maneira que o mercado, internacional e globalizado, substituiu o papel do Estado em razão de sua atenuada relevância frente ao capital globalizado.

\section{ANÁLISE DOS EFEITOS JURÍDICOS E ECONÔMICOS NO MERCADO PÓS- REFORMA TRABALHISTA.}

De fato, a história demonstra as dificuldades nas tentativas de se alcançar um diálogo entre direito e economia. Com o advento da globalização econômica as teorias economicistas se sobrevalorizaram, e, de igual modo, a relação existente entre economia e política passou a influenciar o direito.

Em outras palavras, o mercado globalizado, como um só a serviço do capital internacional, pressionou os Estados no sentido de alterar sua legislação nacional para abordagens mais próximas de fatores e diretrizes econômicas.

Portanto, o Direito do Trabalho, em todo o globo, se encontra em constante redefinição, de maneira que para todo e qualquer anormalidade econômico, a primeira solução 
que se é apresentada, implica numa "atualização" da legislação trabalhista, que em verdade, mais se caracteriza para uma flexibilização e desregulamentação da proteção estatal.

A última Reforma Trabalhista, Lei n. ${ }^{\circ}$ 13.467/2017, alterou de maneira sem igual à legislação laboral nacional, na medida em que se pautou em caráter exclusivamente econômico. Portanto, inexistiu relação interdisciplinar entre economia e direito, de maneira que a primeira foi o único valor social almejado na elaboração da referida lei.

Por meio da análise dos dados que se apresentará na sequência, evidencia-se, de maneira cristalina, que a presunção econômica de que flexibilizar e desregulamentar a legislação laboral com o intuito de criação de novos empregos não se sustenta, ao passo que a pobreza abarcada pela flexibilização e desregulamentação em nada consegue ajudar o crescimento econômico.

De fato, claro que com o passar natural dos anos, diariamente, surgem novas profissões, novos modos de trabalhar e novas maneiras de empreender, e, de igual maneira, também são extintos. Não é apenas natural, como esperado que a regulação também acompanhe esse movimento. Contudo, parece ser tendência que as modificações na legislação laboral, com o intuito de acompanhar as evoluções econômicas e sociais, se limitem à restrição de direitos (MACHADO, 2019).

Isso se confirma, pois, desde o ano de 2003, há forte índice de crescimento da participação do salário na formação do Produto Interno Bruto (PIB).

Hoje, no Brasil, se ultrapassa os 50\%, e a tendência é seguir ganhando força. Ou seja, cada vez mais o salário recebido pelos trabalhadores brasileiros possui maior peso na produção de riquezas do país. Portanto, qualquer política pública respeitosa que, de fato, buscasse crescimento econômico, deveria planear o fortalecimento salarial. (SOUSA FILHO, 2019).

Analisando o mercado exterior, em março de 2017, a taxa de desemprego era de 22,5\% da população da Grécia e, com relação à Espanha o percentual estava em 18,75\%. Ainda, nos EUA a taxa pontuava em 4,5\%. (TRADING ECONOMICS, 2019).

Com relação à taxa de desemprego nacional, em maio de 2017, o Brasil somava 13,3\% de desempregados. Esse marco foi o fundamento para a defesa da necessidade da reforma trabalhista, pois se estimava que o principal efeito fosse a criação de quase seis milhões de novos postos de trabalho, sendo todos com carteira assinada, portanto, formais.

No primeiro ano de vigência da Lei n. ${ }^{\circ}$ 13.467/2017, nem mesmo 300 mil empregos tinham sido criados e, atualmente, 13 milhões de brasileiros (12\% da força de trabalho do país) continuam na procurando por ocupação. Dentro desse percentual, o caso dos jovens é ainda 
mais preocupante, ao passo que $28 \%$ das pessoas entre 18 e 24 anos permanecem desempregadas (TRINDADE, 2019).

Ainda com relação a taxa de desemprego no país, em 2014 pontuava 7\% e, desde 2017 a desocupação nacional estabilizou-se entre aproximadamente $12 \%$ a $13 \%$. Entretanto, vale destacar que a metodologia adotada pelo Instituto Brasileiro de Geografia e Estatística (IBGE), na elaboração do índice de desemprego, passou a classificar como ocupados até mesmo os trabalhadores informais, voluntários e aqueles que não procuram emprego independentemente do motivo (TRINDADE, 2019).

Assim, após pouco mais de dois anos de vigência da Reforma Trabalhista, a mesma não apenas deixou de gerar empregos, como fez estabilizar o desemprego em grande escala.

Isso, pois, desde o início de sua vigência, os empregados informais seguiram crescendo e não há qualquer sinal de arrefecimento. Em todas as atividades, é o grupo de informais que encontra-se em expansão, fazendo com que empregados sem carteira assinada e autônomos sem registro de pessoa jurídica já somem 40,6\% dos ocupados no Brasil (TRINDADE, 2019).

Para, além disso, entre metade de 2016 e início de 2017, os empregados "oficiais" caíram 2,3\% da fatia dos ocupados, enquanto os informais subiram 1,5\%. Assim, são os informais aqueles que puxam para baixo a taxa de desemprego, fazendo com que o índice tenha passado de $13,1 \%$ no $1^{\circ}$ trimestre de 2019 para $12,4 \%$ no segundo período (VALOR ECONÔMICO, 2019).

Ainda, entre abril e junho de 2018, o Brasil perdeu quase meio milhão de postos de trabalho formais. E, conforme apuração do Sistema de Proteção ao Crédito (SPC), entre janeiro e junho de 2018, 64,4\% da população já fez algum tipo de trabalho informal. No mesmo período, em 2019, o índice ficou de 57,4\% (G1, 2019).

Nos meses posteriores à vigência da nova lei, a participação da renda informal na receita familiar já crescia ao ponto de chegar à média de 16,6\% do bolo. Entretanto, para os mais pobres, a participação informal alcança 70\% do orçamento doméstico (TRINDADE, 2019).

Essa crescente taxa de informalidade alimenta-se pelo fato de que a própria lei parece estimular e permitir a fraude do vínculo de emprego, seja com figuras contratuais novas, seja nas dificuldades impostas para reconhecimento judicial de relações empregatícias.

Por meio de pesquisa feita pelo Cadastro Geral de Empregados e Desempregados (CAGED) do Ministério da Economia, desde a entrada em vigor da referida lei, em novembro de 2017 , até setembro de 2019, foram criadas 115,3 mil vagas na modalidade de trabalho 
intermitente, numero esse que representa $12 \%$ do total de vagas criadas no mesmo período no país. (G1, 2019).

Entretanto, numa visão macroeconômica com relação às vagas de trabalho intermitentes, até dezembro de 2019 , já respondiam por $27 \%$ do total de empregos formais existentes no país. (VALOR ECONÔMICO, 2019).

É importante destacar que cerca de $60 \%$ do PIB nacional é constituído por salários e benefícios previdenciários. É essencialmente a partir do salário que se programa a arrecadação de impostos, garante-se o funcionamento do mercado de consumo e alimenta-se a poupança interna (TRINDADE, 2019).

Nesse contexto e de acordo com dados do Departamento Intersindical de Assessoria Parlamentar (DIAP) o reajuste médio de salário em 2017 foi de 5\%. Em 2018, está um pouco acima da metade, em 2,8\% o que já significou redução média de R \$14,00 por empregado (DIAP, 2019).

Para além da estagnação de salários, há outros dados relevantes. Conforme levantamento do Cadastro Geral de Empregados e Desempregados (CAGED), o mercado de trabalho vem se movimentando no sentido de dispensar, principalmente, aqueles trabalhadores que possuem maiores rendimentos (CAGED, 2018).

Apenas em 2018, já houve redução de 43 mil postos de gerência, e, segundo o IBGE, houve soma de $5 \%$ de gestores atuando sem registro em carteira de trabalho. No total, naquele ano, houve cerca de 15 milhões de demissões e, em 2019, o numero ficou em 11,7 milhões (IBGE, 2018).

Ainda, o referido Instituto constatou que houve significado avanço de trabalho autônomo no Brasil, na medida em que nos últimos dois anos, $23 \%$ da força ocupacional do país afirmou ter se tornado autônomo. O problema, segundo a mesma pesquisa, situa-se no fato de que a referida migração não significou melhoria de condições de vida, ao passo que reduziu cerca de $33 \%$ da renda média dos trabalhadores.

De acordo com levantamento da Organização para a Cooperação e Desenvolvimento Económico (OCDE) 32,9\% da força de trabalho brasileira já se ocupa a partir de trabalho autônomo. E, em pesquisa realizada pelo IBGE com relação à renda mensal média no país, verifica-se a de empregados formais em $\mathrm{R} \$ 2.033,00$; empregados informais em $\mathrm{R} \$ 1.206,00 \mathrm{e}$ autônomos em R \$ 1.532,00.

Assim, o autônomo ganha aproximadamente $24 \%$ a menos que empregados formais, além de, majoritariamente, estar desabrigado de benefícios estatais (TRINDADE, 2019). 
Portanto, a Reforma Trabalhista, em razão de todas as dificuldades impostas no tocante ao vínculo de emprego, ocasionou o crescimento do trabalho autônomo, bem como promoveu redução da renda dos trabalhadores e ampliou o desabrigo perante a Previdência, ao afastar o recolhimento de impostos.

Para, além disso, com relação aos efeitos da Reforma no Poder Judiciário, enquanto que em janeiro de 2017 houve 200 mil ajuizamentos de demandas trabalhistas, o mesmo período de 2018 contou pouco mais de 84,2 mil novas ações. E, na média nacional, se reduziu cerca de 40\% no número de processos (TRINDADE, 2019).

Por fim, da mesma forma que o desemprego aumenta, também crescem as mazelas do mundo. O Brasil é o décimo país mais desigual do mundo de acordo com o Programa das Nações Unidas para o Desenvolvimento (PNUD), de maneira que metade dos brasileiros vivem com apenas $\mathrm{R} \$ 413,00$ por mês (IBGE, 2019).

Segundo a mesma pesquisa, 5\% da população (10,4 milhões de brasileiros) sobrevivem com apenas $\mathrm{R} \$ 51,00$ mensais, em média. No outro extremo, $1 \%$ da população apresenta renda acima de $\mathrm{R} \$ 16.297,00$ mensais (IBGE, 2019).

Enfrenta-se hoje, talvez, as consequências do espólio do isolacionismo do conhecimento científico que, portanto, impossibilitam uma efetiva comunicação entre direito e economia com a adoção conjunta de metodologia interdisciplinar a fim de se complementarem na busca por soluções conjuntas.

Parece que a atual conjectura mundial está revivendo as mesmas ambições que alimentaram a primeira revolução industrial, ao passo que o caminho da minimização dos gastos para maximização dos lucros, cada vez mais, se destaca.

Prevalece, portanto, a lei do mercado, de maneira que passou a ser o empregador aquele que dita às regras do jogo, num Estado afastado e enfraquecido que, agora, pouco pode fazer em razão do forte incentivo a liberdade contratual.

Permanece a indagação feita por Dworkin (1986) ao se questionar sobre até que ponto a riqueza, em detrimento da justiça, como ideal metajurídico deve ser o motivador da norma? A globalização econômica parece já ter escrito sua resposta.

\section{CONSIDERAÇÕES FINAIS}

No plano nacional, a Constituição de 1988, em seu capítulo II, intitulado: "Dos Direitos Sociais", dispõe em seu artigo $6^{\circ}$, entre outros, que são direitos sociais o trabalho na 
forma da Constituição. Ainda, o artigo $7^{\circ}$ prescreve os direitos dos trabalhadores, além de outros, que visem à melhoria de sua condição social (MARTINS; GUNTHER; VILATORE, 2019, p. 34).

Assim, a Carta Magna supervalorizou o ser humano. Para tanto, o constituinte manifestou seu desejo de alterar o eixo de prioridade, passando do Estado para o próprio homem (LENZA, 2011). A atenção passou a ser mais intensiva para com o indivíduo. Contudo, não significa que está se protegendo somente o trabalhador, mas a todos os indivíduos.

A Justiça do Trabalho, uma das expressões do Estado social, está prevista na atual Constituição brasileira de 1988 em seus artigos $6^{\circ}, 7^{\circ}$ e $8^{\circ}$ (BRASIL, 1988), de maneira que buscou fortificar os direitos sociais tendo em vista a dicotomia entre empregado e empregador.

Portanto, a tutela dos direitos trabalhistas a fim de se garantir proteção em face de um cenário desfavorável e desproporcional, se faz necessária por meio da intervenção estatal que se depara com a realidade posta e não com aquela realidade pressuposta e textualizada na letra da lei (MARTINS; GUNTHER; VILATORE, 2019, 144).

$\mathrm{O}$ acesso à justiça aos tribunais já foi considerado como concretização do princípio estruturante do Estado de Direito. Portanto, a estrutura normativa constitucional brasileira não destoa dessa premissa, ao passo que possui compromissos internos e externos, com outras plataformas de Direito vinculando-se, portanto, ao plano internacional à tutela a essa garantia constitucional (CANOTILHO, 2003).

Assim, a garantia ao acesso à justiça em plano interno, não é uma característica de Estado paternalista, mas de um modelo estatal que, além de respeitar e fazer valer suas regras constitucionais, também é indissociável o ideal de garantir o acesso à justiça. Portanto, característica de um Estado Democrático de Direito.

A justiça, portanto, é condição para existência digna, fundamento do pacto social, ao qual decorrem a ordem econômica e a ordem social, que entre si, são constitucionalmente inseparáveis.

O modelo de Estado assumido pelo constituinte de 1988, caracteriza-se em uma coexistência entre a livre iniciativa e proteção social. Entretanto, não significa o sufocamento de um em favor do outro, pois a ordem econômica e a ordem social, para além de compartilharem de um mesmo princípio (justiça social) devem ser interpretadas em conjunto com o artigo $3^{\circ}$ da Constituição, ao qual explicita a proclamação do projeto regente da República Federativa do Brasil (DE MELLO, 2019).

Nessa leitura, a previsão normativa do princípio da intervenção mínima inaugurou movimento do direito do trabalho mínimo, o que significa tutela mínima a direitos sociais e, 
assim, inaplicável ao direito do trabalho vez que se revela, portanto, inconstitucional MARTINS; GUNTHER; VILATORE, 2019, 144).

Uma vez sendo o Direito do Trabalho, valor social, exige-se uma prestação e intervenção positiva do Estado, ou seja, de um modelo cujos direitos sociais deveriam estar intrinsecamente conectados à possibilidade de o Estado efetivá-los. Assim, a valorização do trabalho humano, por ser princípio integrante da ordem econômica, sempre deve prevalecer como prioridade em relação aos interesses puramente econômicos.

Assim, o Princípio da Intervenção Mínima deveria ser inaplicável ao direito do trabalho, ante sua incompatibilidade frente aos fundamentos e princípios constitucionais constantes no domínio econômico e domínio social que se regem sob a ótica deontológica da justiça social, como sendo, também, patamar axiológico supremo do Título II, Capítulo II da Constituição de 1988 - "Dos Direitos Sociais".

Por meio dos dados apresentados, ficou constatado que, a teoria econômica de se flexibilizar a legislação trabalhista com o intuito de gerar empregos não se sustenta, na medida em que a pobreza abarcada pela flexibilização e desregulamentação, em nada favorece o crescimento econômico, isso, posto que o consumidor final é o próprio trabalhador.

Por fim, na medida em que o mercado também constitui lugar de relações sociais, os fundamentos econômicos deveriam se confrontar com um modelo de sustentabilidade que diga respeito ao modo como o funcionamento do mercado pode contribuir para assegurar vida digna. A questão da sustentabilidade, nesse sentido, não se refere apenas à viabilidade de desenvolvimento econômico e tecnológico, mas deve atingir patamar inclusivo para subordinar o processo de produção aos escopos de um efetivo Estado Democrático de Direito.

\section{REFERÊNCIAS}

BRASIL. Constituição da República dos Estados Unidos do Brasil de 1891. Disponível em: http://www.planalto.gov.br/ccivil_03/Constituicao/Constituicao91.htm Acesso em 10 de dezembro de 2019.

BRASIL. Constituição da República dos Estados Unidos do Brasil de 1934. Disponível em: http://www.planalto.gov.br/ccivil_03/constituicao/constituicao34.htm. Acesso em 15 de dezembro de 2019. 
BRASIL. Constituição da República Federativa do Brasil de 1967. Disponível em: http://www.planalto.gov.br/ccivil_03/constituicao/constituicao67.htm. Acesso em 15 de dezembro de 2019.

BRASIL. Constituição da República Federativa do Brasil de 1988. Disponível em: <http://www.planalto.gov.br/ccivil_03/constituicao/constituicao.htm>. Acesso em 14 de janeiro de 2020.

BRASIL. Constituição dos Estados Unidos do brasil de 1946. Disponível em: http://www.planalto.gov.br/ccivil_03/constituicao/constituicao46.htm. Acesso em 15 de dezembro de 2019.

BRASIL. Constituição Política do Império do Brazil de 1824. Disponível em: http://www.planalto.gov.br/ccivil_03/constituicao/constituicao24.htm. Acesso em 18 de dezembro de 2019.

BRASIL. Lei no 13.467, de 13 de julho de 2017 (Lei da Reforma Trabalhista). Disponível em: <http://www.planalto.gov.br/ccivil_03/_ato2015-2018/2017/lei/113467.htm>. Acesso em 14 de janeiro de 2020.

CAGED. Nove Meses Depois: o que a Reforma Trabalhista Entregou ao Mercado de Trabalho Brasileiro. 2018. Disponível em: http://revisaotrabalhista.net.br/2018/08/13/novemeses-depois-o-que-a-reforma-trabalhista-entregou-ao-mercado-de-trabalho-brasileiro/. Acesso em: 05 de janeiro de 2020.

CALDAS, Camilo Onoda. O Estado; organizadores Marcelo Semer, Marcio Sotelo Felippe. $1^{\text {a }}$ ed. São Paulo, Estúdio Editores.com, 2014.

CANOTILHO, J.J. Gomes. Direito Constitucional e Teoria da Constituição. $3^{\mathrm{a}}$ ed. Coimbra: Almedina, 1988.

CASSAR, Vólia Bomfim. Direito do Trabalho. Rio de Janeiro, $3^{\text {a }}$ ed. Impitus, 2014.

DALlARI, Dalmo de Abreu. Elementos de Teoria Geral do Estado. 22a ed. São Paulo, Saraiva, 2001.

DE MELLO, Celso Antônio. Curso de Direito Administrativo. $34^{a}$ ed. São Paulo: Malheiros, 2019.

DELGADO, Mauricio Godinho; DElGADO, Gabriela Neves. A Matriz da Constituição de 1988 Como Parâmetro Para a Análise da Reforma Trabalhista. In: GUNTHER, Luiz Eduardo; JÚNIOR, Hélio Gomes Coelho. Novas Matrizes do Direito do Trabalho. São Paulo: LTr, 2019, p.47 - p.56.

DIAP. Produtividade sobre mais que salários na indústria, avaliam economistas. 2019. 
http://www.diap.org.br/index.php?option=com_content\&view=article\&id=13489:produtivida de-sobe-mais-que-salarios-na-industria-avaliam-economistas\&catid=35:agenciadiap\&Itemid=206. Acesso em: 16 de janeiro de 2020.

DWORKIN, Ronald. A Matter of Principle. Oxford: Clarendon, 1986.

G1 GLOBO. Desemprego sobre para 12,4\% em fevereiro, diz IBGE. 2019. Disponível em: https://g1.globo.com/economia/concursos-e-emprego/noticia/2019/11/11/reforma-trabalhistacompleta-2-anos-veja-os-principais-efeitos.ghtml. Acesso em 10 de janeiro de 2020.

G1 GLOBO. Reforma Trabalhista Completa 2 anos; veja os principais efeitos. 2019. Disponível em: https://g1.globo.com/economia/concursos-eemprego/noticia/2019/11/11/reforma-trabalhista-completa-2-anos-veja-os-principaisefeitos.ghtml. Acesso em: 10 de janeiro de 2020.

IBGE. Metade dos Brasileiros vive com apenas R\$ 413 por mês. 2019. Disponível em: https://noticias.r7.com/economia/metade-dos-brasileiros-vive-com-apenas-r-413-por-mesmostra-ibge-16102019. Acesso em: 17 de janeiro de 2020.

IBGE. Taxa de Desocupação Trimestre. 2018-2019. Disponível em: https://www.ibge.gov.br/busca.html?searchword=\%C3\%8DNDICE+desemprego+2019. Acesso em: 10 de janeiro de 2020.

LENZA, Pedro. Direito Constitucional Esquematizado. 15. ed. São Paulo: Saraiva, 2011. MACHADO, Sidnei. A Reforma Trabalhista no Brasil a Partir de uma Perspectiva Comparada das Reformas na União Europeia. In: GUNTHER, Luiz Eduardo; JÚNIOR, Hélio Gomes Coelho. Novas Matrizes do Direito do Trabalho. São Paulo: LTr, 2019, p.41 p.46.

MARINHO, Josaphat. A Ordem Econômica nas Constituições Brasileiras. Direito Constitucional. Constituição Financeira Econômica e Social. São Paulo: vol. 6, n. 0549, revista dos tribunais, 2011.

MARTINS, Gustavo Afonso; GUNTHER, Luiz Eduardo; VILLATORE, Marco Antônio César. O Princípio da Intervenção Mínima e o Acesso à Justiça do Trabalho. Curitiba: Instituto Memória. Centro de Estudos da Contemporaneidade, 2019.

MIRANDA, Jorge. Ciência Política: formas de governo. Lisboa, Rio de Mouro, 1996.

MIRANDA, Jorge. Teoria do Estado e da Constituição. Rio de Janeiro, 2005.

SOUSA FILHO, Georgenor de. Perspectivas para o Mundo do Trabalho, do Direito do Trabalho e da Justiça do Trabalho. In: GUNTHER, Luiz Eduardo; JÚNIOR, Hélio Gomes Coelho. Novas Matrizes do Direito do Trabalho. São Paulo: LTr, 2019, p.13 - p.19. 
TRADING ECONOMICS, 2019. Disponível em: https://pt.tradingeconomics.com/countrylist/unemployment-rate. Acesso em 13/01/2020. Acesso em 10 de janeiro de 2020.

TRINDADE, Rodrigo. Dois Anos Depois: Efeitos Jurídicos e Econômicos dos Dez (Novos) Princípios de Direito (Empresarial) do Trabalho. In: GUNTHER, Luiz Eduardo; JÚNIOR, Hélio Gomes Coelho. Novas Matrizes do Direito do Trabalho. São Paulo: LTr, 2019, p.57 p.74.

VALOR ECONÔMICO. Vaga Intermitente Responde por $27 \%$ do Novo Emprego Formal. 2019. Disponível em: https://valor.globo.com/brasil/noticia/2019/12/09/vaga-intermitenteresponde-por-27-do-novo-emprego-

formal.ghtml?origem=G1\&utm_source=g1.globo.com\&utm_medium=referral\&utm_campaig $\mathrm{n}=$ materia. Acesso em 08 de janeiro de 2020.

VILLATORE, Marco Antônio César; GUNTHER, Luiz Eduardo. GLOBALIZATION, ECONOMIC CRISIS AND COLLECTIVE BARGAINING IN INTERNATIONAL LABOR LAW. Revista Juridica, [S.1.], v. 51, n. 2, p. 137 - 165, abr. 2018. ISSN 2316-753X. Disponível em: $<$ http://revista.unicuritiba.edu.br/index.php/RevJur/article/view/2803/371371471>. Acesso em: 19 abr. 2020. doi:http://dx.doi.org/10.21902/revistajur.2316-753X.v51i2.2803. 